\title{
Hospital Admission and Readmission Among US Patients Receiving Umeclidinium/Vilanterol or Tiotropium as Initial Maintenance Therapy for Chronic Obstructive Pulmonary Disease
}

\author{
David Slade · Riju Ray (D) C Chad Moretz (D) - Guillaume Germain (D) • \\ François Laliberté · Qin Shen · Mei Sheng Duh (D) · Sean D. MacKnight • \\ Beth Hahn (D)
}

Received: December 3, 2020 / Accepted: February 15, 2021 / Published online: March 17, 2021

(c) The Author(s) 2021

\begin{abstract}
Introduction: Patients hospitalized for chronic obstructive pulmonary disease (COPD) exacerbations are at risk of further readmissions, increased treatment costs, and excess mortality. This study evaluated inpatient admissions and readmissions in patients receiving initial maintenance therapy with umeclidinium/vilanterol (UMEC/VI) versus tiotropium (TIO).

Methods: This retrospective, matched cohort study identified patients with COPD who initiated maintenance therapy with UMEC/VI or TIO from Optum's de-identified Clinformatics Data Mart database between January 1, 2013, and
\end{abstract}

Supplementary Information The online version contains supplementary material available at https:// doi.org/10.1007/s41030-021-00151-y.

D. Slade $\cdot$ R. Ray

US Medical Affairs, GSK, Research Triangle Park, NC, USA

C. Moretz · B. Hahn ( $\square)$

US Value Evidence and Outcomes, GSK, Research

Triangle Park, NC, USA

e-mail: Beth.a.hahn@gsk.com

G. Germain · F. Laliberté · S. D. MacKnight Groupe D'Analyse, Ltée, Montréal, QC, Canada

Q. Shen

GSK, Collegeville, PA, USA

M. S. Duh

Analysis Group, Inc., Boston, MA, USA
December 31, 2018 (index date defined as earliest dispensing). Eligibility criteria included: $\geq 1$ medical claim for COPD pre-index or on the index date; $\geq 12$ months of continuous eligibility pre-index; age $\geq 40$ years at index; no pre- or post-index asthma diagnosis; and no pre-index claims for medications containing inhaled corticosteroids, long-acting $\beta_{2}$-agonists, or longacting muscarinic antagonists. Outcomes included time to first on-treatment COPD-related inpatient admission, rate of on-treatment COPDrelated admissions, and rate of all-cause and COPD-related readmissions within 30 and 90 days. Propensity score matching was used to adjust for potential confounders.

Results: Matched UMEC/VI and TIO cohorts each included 7997 patients and were balanced on baseline characteristics (mean age 70.9 years; female 47.1-47.6\%). Over 12 months, patients initiating UMEC/VI had significantly reduced risk (hazard ratio [95\% CI]: $0.87 \quad[0.79, \quad 0.96]$; $p=0.006$ ) and rates (rate ratio [95\% CI]: 0.80 $[0.72,0.92] ; p=0.008$ ) of COPD-related inpatient admissions compared with TIO. While all-cause readmission rates were similar between treatment cohorts, readmission rates among patients with an initial admission length of stay of 1-3 days were numerically lower for UMEC/VI versus TIO (30-day readmissions: $10.5 \%$ vs. $12.4 \%$; 90-day readmissions: $15.5 \%$ vs. $19.8 \%$ ). Similar patterns were observed for COPD-related readmissions.

Conclusions: These findings highlight the realworld benefits of dual therapy with UMEC/VI 
versus TIO in reducing inpatient admissions and readmissions in patients with COPD, which may translate to lower healthcare costs.

\section{PLAIN LANGUAGE SUMMARY}

Patients with chronic obstructive pulmonary disease (COPD) who are admitted to the hospital are more likely to be readmitted in the future, have higher healthcare costs, and are more likely to die from their illness. Patients who are readmitted to hospital have even higher treatment costs. Identifying which treatments are best at reducing the number of patients with COPD who are admitted to the hospital may help to improve outcomes and reduce the cost of COPD treatment. We used US healthcare claims data to compare two daily treatments for COPD, umeclidinium/vilanterol and tiotropium. We aimed to find out which treatment was more effective at reducing hospital admissions due to COPD. We also compared how many patients on each treatment were readmitted within 30 or 90 days of their original hospital admission for COPD. We found that patients who started treatment with umeclidinium/vilanterol were less likely to be admitted to the hospital for COPD than patients who started treatment with tiotropium. Similar numbers of patients on each treatment were readmitted to the hospital within 30 or 90 days after they were discharged. However, among patients whose initial hospital stay was short (1-3 days), readmissions within 30 or 90 days were less common with umeclidinium/ vilanterol than tiotropium. These findings suggest that umeclidinium/vilanterol may be more effective than tiotropium at reducing the number of patients with COPD who need to be admitted or readmitted to hospital. Starting COPD treatment with umeclidinium/vilanterol may lead to better health outcomes and lower costs than tiotropium.

Keywords: COPD; Hospitalization; Initial maintenance therapy; Inpatient admission; LAMA; LAMA/LABA; Readmission; UMEC/VI; Tiotropium; Umeclidinium/vilanterol

\section{Key Summary Points}

Why carry out this study?

Patients with chronic obstructive pulmonary disease (COPD) who are admitted to hospital for COPD exacerbations are at elevated risk of hospital readmissions, greater treatment costs, and excess mortality.

Clinical trials have demonstrated significantly greater improvements in lung function, symptoms, and healthrelated quality of life with the long-acting muscarinic antagonist/long-acting $\beta_{2}$-agonist (LAMA/LABA) dual therapy umeclidinium/vilanterol (UMEC/VI) compared with the LAMA monotherapy tiotropium; however, few studies have compared these treatments in the realworld setting on clinical outcomes such as hospitalizations.

This claims-based retrospective study assessed the impact of initiating maintenance therapy with UMEC/VI versus TIO on COPD-related inpatient admissions and readmissions in patients with COPD.

\section{What was learned from the study?}

Patients receiving UMEC/VI compared with TIO had significantly reduced risk and rates of COPD-related inpatient admissions. Readmission rates among those who had a short length of stay (1-3 days) at their initial admission were numerically lower for the UMEC/VI cohort than the TIO cohort.

These findings highlight the real-world benefits of dual therapy with UMEC/VI versus TIO in reducing inpatient admissions and potentially reducing readmissions in patients with COPD, which may translate to lower healthcare costs. 


\section{DIGITAL FEATURES}

This article is published with digital features, including a summary slide and plain language summary, to facilitate understanding of the article. To view digital features for this article go to https://doi.org/10.6084/m9.figshare.13953734.

\section{INTRODUCTION}

Exacerbations of chronic obstructive pulmonary disease (COPD) are characterized by an acute worsening of symptoms that necessitates additional treatment to achieve control, and are associated with increased healthcare resource utilization (HRU) and costs [1-3]. Severe COPD exacerbations can necessitate inpatient hospital admission, which has been linked to an increased risk of subsequent readmission and mortality [2, 4-8]. Inpatient readmissions are associated with a $20 \%$ increase in healthcare costs over the original inpatient admission event [6]. For hospitals and payers, readmission costs are further increased due to financial penalties levied by the Centers for Medicare and Medicaid Services (CMS) against hospitals with excess inpatient readmissions within 30 days for patients with COPD $[9,10]$. These cost implications highlight the importance of identifying treatments that can reduce inpatient admissions and readmissions.

In clinical trials, patients with COPD treated with the long-acting muscarinic antagonist/longacting $\beta_{2}$-agonist (LAMA/LABA) dual therapy umeclidinium/vilanterol (UMEC/VI) demonstrated significantly greater improvements in lung function, symptoms, and health-related quality of life compared with patients receiving the LAMA monotherapy tiotropium (TIO) [11-13]. A cost-effectiveness analysis also found that UMEC/VI is associated with lower lifetime medical costs than TIO [14]. However, no published studies have yet compared these treatments on real-world outcomes that are relevant to patients' disease burden and treatment costs, such as inpatient admission and readmission rates.

The objective of this study was to assess the impact of initiating maintenance therapy with
UMEC/VI versus TIO on COPD-related inpatient admissions and readmissions in patients with COPD.

\section{METHODS}

\section{Data Source and Study Design}

This was a retrospective matched cohort study using healthcare insurance claims from Optum's de-identified Clinformatics Data Mart database, with data ranging from January 1, 2013, to December 31, 2018. The database comprises claims data from a geographically diverse population of 12-14 million United Health Group members, including both commercial and Medicare Advantage health plan data, and contains historical data on patient demographics, insurance coverage, dates of eligibility and death, claims for inpatient and outpatient visits, costs of services, and filled prescriptions.

The study was designed and conducted in accordance with the principles of the 1964 Declaration of Helsinki and its later amendments. The study used fully de-identified retrospective claims data, which were compliant with the patient requirements of the Health Insurance Portability and Accountability Act of 1996 (HIPAA), and as such was not classified as research involving human participants. Therefore, institutional review board approval was not required.

The index date was defined as the date of the first pharmacy claim for UMEC/VI or TIO during the identification period, which spanned from January 1, 2014, to December 31, 2018 (Fig. 1). Patients were classified into mutually exclusive cohorts based on their index medication (UMEC/VI or TIO). The on-treatment period was defined as the period from the index date to the date of a pharmacy fill for a nonindex maintenance medication (i.e., inhaled corticosteroid [ICS], LABA, or LAMA), discontinuation of the index medication, end of continuous eligibility, end of data availability, or death. Discontinuation was defined as a $\geq 45$ day gap ( $\geq 115$ days for mail orders) between the end of a dispensing and the next fill, or between the end of the last dispensing and the 


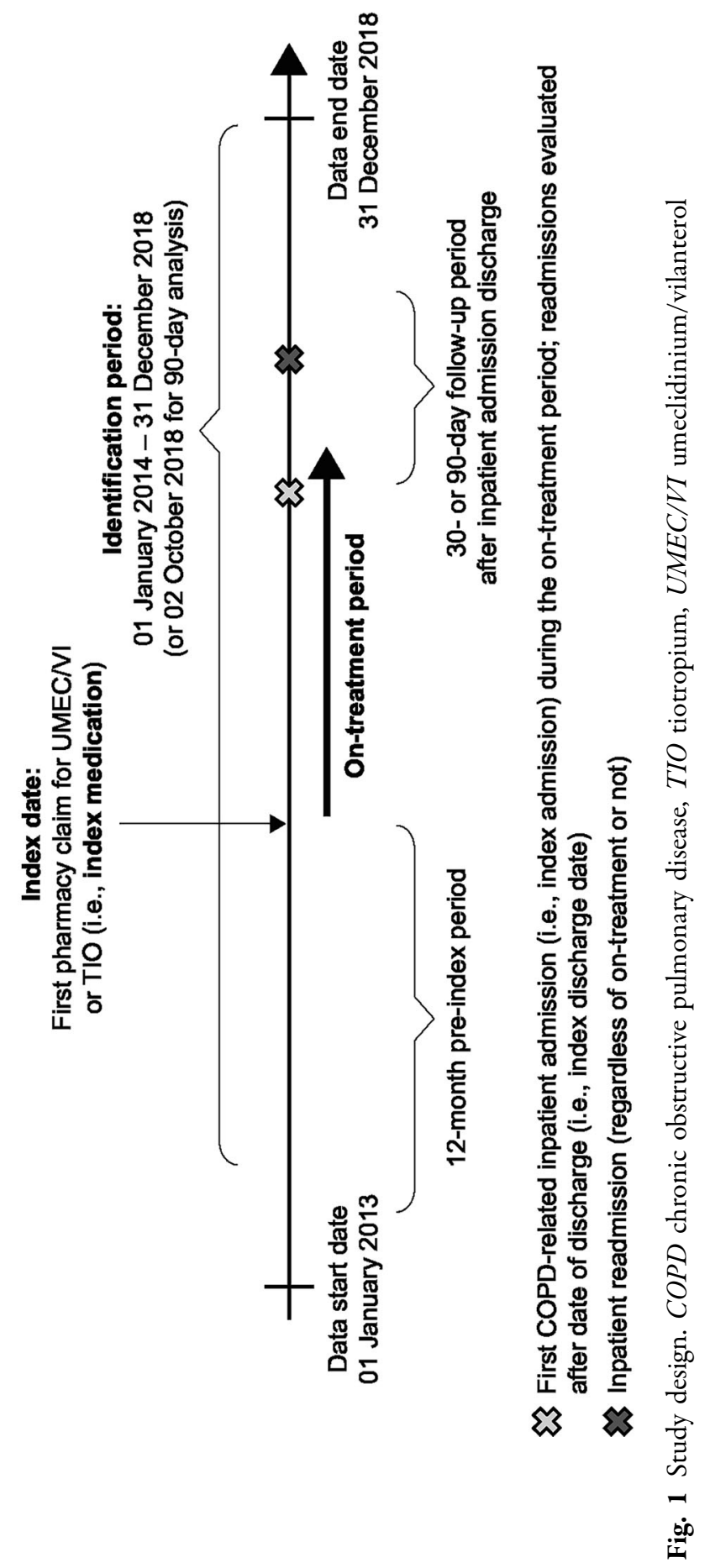


end of data availability. For the analysis of inpatient readmissions, the follow-up period was defined as the 30-day or 90-day period after the index discharge date (defined as the discharge date for the first COPD-related inpatient admission during the on-treatment period) (Fig. 1).

\section{Study Population}

Patients included in the primary analysis of inpatient admissions were $\geq 40$ years of age at index, and were required to have: $\geq 1$ pharmacy claim for UMEC/VI or TIO (via dry-powder inhaler) during the identification period; $\geq$ 12 months of continuous medical and pharmacy coverage during the pre-index period; and $\geq 1$ medical claim with a diagnosis for COPD during the 12-month pre-index period, or on the index date. A complete list of International Statistical Classification of Diseases and Related Health Problems (ICD) codes used to identify claims for COPD and COPD exacerbations is included in Table S1 (in the electronic supplementary material). Patients were excluded if they had: $\geq 1$ pharmacy claim for maintenance medication containing ICS, LABA, or LAMA during the 12-month pre-index period; $\geq 1$ pharmacy claim on the index date for both UMEC/VI and TIO, a non-index controller medication, or single- or multiple-inhaler triple therapy (ICS/LAMA/LABA); or $\geq 1$ medical claim with a diagnosis for asthma any time prior to or after the index date (ICD 9th Edition Clinical Modification codes: 493.xx; ICD 10th Edition Clinical Modification codes: J45.3x, J45.4x, J45.5x, J45.9xx).

Patients included in the readmission analysis were also required to have $\geq 1$ COPD-related admission during the on-treatment period, to be alive at the index discharge date, and to have continuous medical and pharmacy coverage for $\geq 30$ or $\geq 90$ days after the index discharge date. Readmissions were also evaluated among a subgroup of patients with a short initial COPDrelated admission (length of stay [LOS] of 1-3 days).

\section{Outcomes}

The primary outcome was time to first COPDrelated inpatient admission during the ontreatment period, defined as an inpatient admission with a primary or secondary diagnosis of COPD (Table S1 in the electronic supplementary material). Secondary outcomes included the rate of COPD-related inpatient admissions during the on-treatment period (up to 12 months post-index) and the rate of allcause and COPD-related inpatient readmissions within 30 and 90 days of the index discharge date. Readmission rates were assessed regardless of whether patients were on treatment at the time of readmission; medication changes after the initial inpatient admission were reported.

\section{Statistical Analysis}

Patients in the UMEC/VI and TIO cohorts were matched (1:1) using propensity score matching based on probability estimates from a logistic regression model including the following baseline covariates: age, sex, region, insurance type, year and quarter of index date, Quan-Charlson Comorbidity Index (CCI) score, proportion of patients with pre-index moderate and severe exacerbations, respiratory medications (including systemic corticosteroids, short-acting $\beta_{2}$-agonists [SABA], short-acting muscarinic antagonists [SAMA], and SABA/SAMA combinations), HRU, medical costs, and Elixhauser [15] and Diagnostic and Statistical Manual-V (DSM-V) comorbidities with a prevalence $\geq 5 \%$ in either cohort (Table S2 in the electronic supplementary material).

Descriptive statistics for patient characteristics during the pre-index period included means and standard deviations (SD) for continuous variables and relative frequencies for categorical variables. The primary outcome was assessed using Kaplan-Meier survival analysis and compared between cohorts using hazard ratios (HR) from Cox proportional hazards regression models. COPD-related inpatient admission rates were reported per 100 person-days and compared using rate ratios (RR) from Poisson regression models; confidence intervals (CI) and 
$p$ values were calculated using non-parametric bootstrap procedures. The proportions of patients in either cohort who switched medication after the initial inpatient admission were reported. The proportions of patients with 30-day and 90-day readmissions were reported, and readmission rates were calculated as the total number of events per patient (not censored after the first event) divided by the total number of patients.

\section{RESULTS}

\section{Study Sample}

Of the 282,263 patients who initiated treatment with UMEC/VI or TIO during the identification period, 11,009 receiving UMEC/VI and 21,039 receiving TIO met the study eligibility criteria and were included in the study (Fig. 2). Following propensity score matching, 7997 patients were included in each treatment cohort.

\section{Patient Demographics and Characteristics}

Patient demographics at index, and clinical characteristics, medication history, and HRU during the pre-index period for unmatched and matched cohorts are shown in Table 1. Matched treatment cohorts had a similar mean age (both 70.9 years), proportion of women (47.1-47.6\%), proportion of Medicare patients (80.0-80.5\%), mean Quan-CCI score (both 3.3), mean exacerbation rate (0.49-0.50 events/year), and COPD-related HRU and medical costs. The most common pre-index Elixhauser comorbidities in the matched UMEC/VI and TIO cohorts were chronic pulmonary disease (89.1-89.8\%), hypertension (75.7-75.8\%), and diabetes (30.9-31.2\%) (Table S2 in the electronic supplementary material). The most common respiratory medications used in the UMEC/VI and TIO cohorts were systemic corticosteroids (46.5-46.7\%) and SABA (both $39.2 \%$ ). After matching, patients treated with UMEC/VI versus TIO had a similar mean eligibility period (474 vs. 468 days) and a longer mean on-treatment period (152 vs. 106 days).

\section{Time to First On-Treatment COPD-Related Inpatient Admission}

Patients treated with UMEC/VI had significantly lower risk of COPD-related inpatient admission compared with those treated with TIO. During up to 12 months of treatment, $24.1 \%$ and $26.1 \%$ of patients receiving UMEC/VI and TIO, respectively, experienced a COPD-related inpatient admission, corresponding to a 13\% lower risk of admission (HR [95\% CI]: 0.87 [0.79, $0.96] ; p=0.006$; Fig. 3). The mean time to first COPD-related admission was 22 days longer for the UMEC/VI cohort than the TIO cohort (88 vs. 66 days).

\section{Rate of On-Treatment COPD-Related Inpatient Admissions}

The rate of COPD-related inpatient admissions was also significantly reduced among patients in the UMEC/VI cohort (0.106 events/100 person-days) compared with the TIO cohort $(0.132$ events/100 person-days), resulting in a $20 \%$ lower rate among patients treated with UMEC/VI versus TIO (RR [95\% CI]: 0.80 [0.72, 0.92]; $p=0.008$ ) (Table 2).

\section{Medication Change After On-Treatment Inpatient Admission}

Of the 840 and 717 patients receiving UMEC/VI and TIO who had an on-treatment inpatient admission and $\geq 30$ days of continuous enrollment post-discharge, 748 (89.0\%) and 613 $(85.5 \%)$ remained on their index treatment at discharge. Among the 74 and 121 patients who switched from UMEC/VI and TIO, the most common therapies used after switching were ICS (45.9\% and 9.9\%) and ICS/LABA (17.6\% and $71.1 \%)$.

\section{Inpatient Readmissions}

Of the 840 and 717 patients who initiated UMEC/VI and TIO and were eligible for the 30-day readmission analysis, $11.7 \%$ in each cohort experienced an all-cause inpatient readmission. Among patients with an initial admission LOS of $1-3$ days, $10.5 \%$ and $12.4 \%$ in 


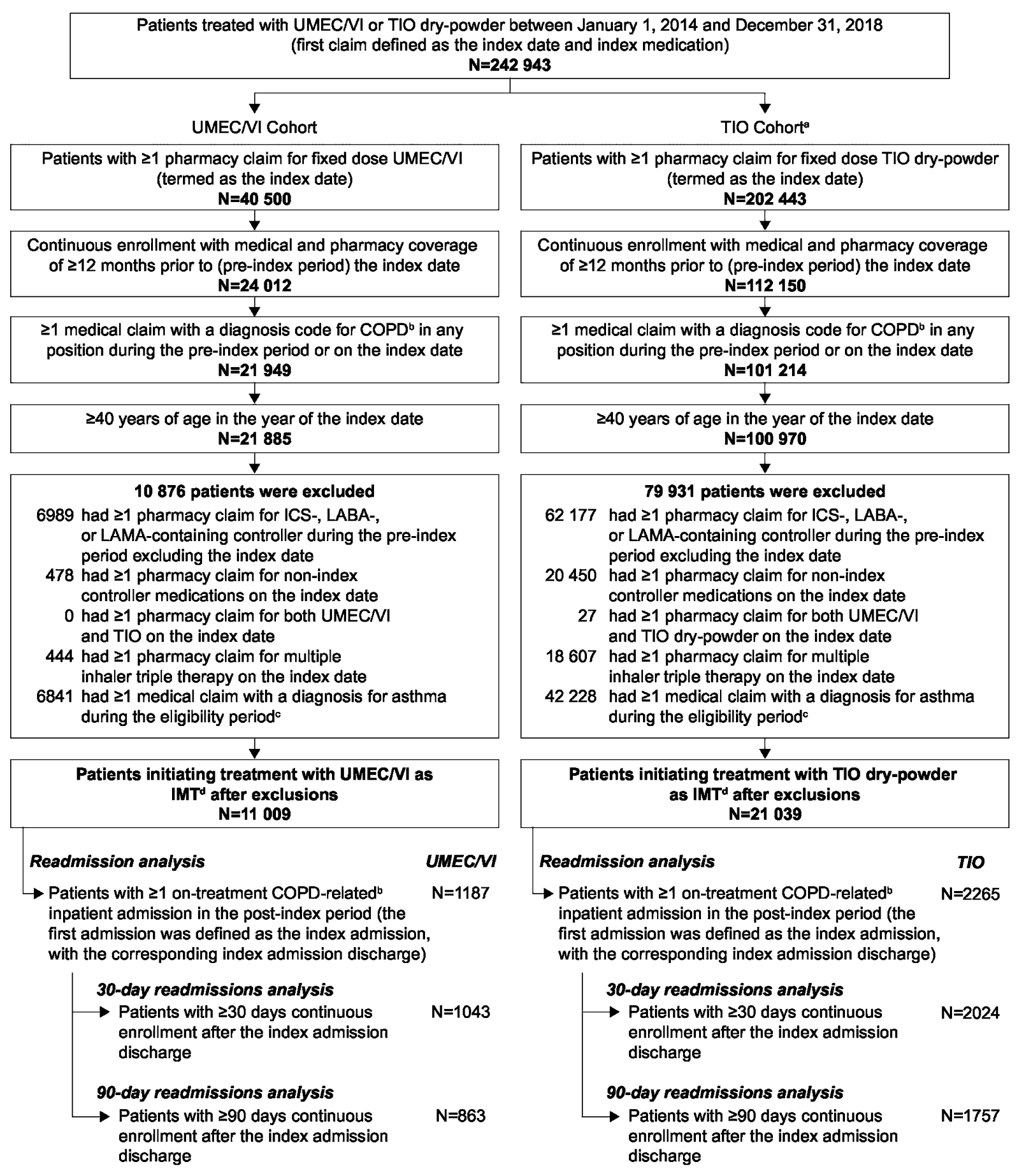

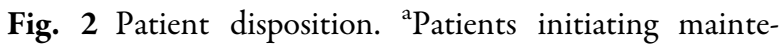
nance therapy with both UMEC/VI and TIO on the index date were classified as TIO and subsequently

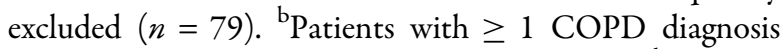
code. ${ }^{\text {CPatients with }} \geq 1$ asthma diagnosis code. ${ }^{\mathrm{d}}$ IMT was defined as no ICS-, LABA-, or LAMA-containing controller prior to the first pharmacy claim for UMEC/VI or

TIO during the identification period. COPD chronic obstructive pulmonary disease, ICS inhaled corticosteroid, $I M T$ initial maintenance therapy, $L A B A$ long-acting $\beta_{2^{-}}$ agonist, $L A M A$ long-acting muscarinic antagonist, TIO tiotropium, $U M E C$ umeclidinium, $V I$ vilanterol 
Table 1 Patient demographics and clinical characteristics during the pre-index period and at index

\begin{tabular}{|c|c|c|c|c|c|c|}
\hline & \multicolumn{3}{|c|}{ Unmatched cohorts } & \multicolumn{3}{|c|}{ Propensity score-matched cohorts } \\
\hline & $\begin{array}{l}\text { UMEC/VI } \\
n=11009\end{array}$ & $\begin{array}{l}\text { TIO } \\
n=21039\end{array}$ & $\begin{array}{l}\text { Standardized } \\
\text { diff. }^{\text {a }}(\%)\end{array}$ & $\begin{array}{l}\text { UMEC/VI } \\
n=7997\end{array}$ & $\begin{array}{l}\text { TIO } \\
n=7997\end{array}$ & $\begin{array}{l}\text { Standardized } \\
\left.\text { diff. }^{\text {a }} \%\right)\end{array}$ \\
\hline $\begin{array}{l}\text { Post-index eligibility } \\
\text { period, }^{\text {b days, mean }} \\
\text { (SD) }\end{array}$ & $422.4(318.3)$ & $717.7(519.2)$ & 68.6 & $474.3(339.4)$ & $467.9(344.2)$ & 1.9 \\
\hline $\begin{array}{l}\text { On-treatment follow-up } \\
\text { period, }^{c} \text { days, mean } \\
(\mathrm{SD})\end{array}$ & $141.8(181.5)$ & $121.0(195.4)$ & 11.0 & $152.4(197.5)$ & $105.5(152.0)$ & 26.6 \\
\hline Age, years, mean (SD) & $70.4(9.8)$ & $71.6(9.7)$ & 12.2 & $70.9(9.8)$ & $70.9(9.8)$ & 0.1 \\
\hline Female, $n(\%)$ & $5036(45.7)$ & $10295(48.9)$ & 6.4 & $3767(47.1)$ & $3806(47.6)$ & 1.0 \\
\hline \multicolumn{7}{|l|}{ Region, $n$ (\%) } \\
\hline South & $5755(52.3)$ & $7626(36.2)$ & 32.3 & $3573(44.7)$ & $3516(44.0)$ & 1.4 \\
\hline West & $1872(17.0)$ & $6134(29.2)$ & 28.8 & $1709(21.4)$ & $1767(22.1)$ & 1.8 \\
\hline Midwest & $2314(21.0)$ & $4797(22.8)$ & 4.3 & $1877(23.5)$ & $1868(23.4)$ & 0.3 \\
\hline Northeast & $1045(9.5)$ & $2418(11.5)$ & 6.5 & $825(10.3)$ & $821(10.3)$ & 0.2 \\
\hline Unknown & $23(0.2)$ & $64(0.3)$ & 1.9 & $13(0.2)$ & $25(0.3)$ & 3.1 \\
\hline \multicolumn{7}{|l|}{ Insurance plan type, $n$ (\%) } \\
\hline Medicare & $8633(78.4)$ & $17327(82.4)$ & 9.9 & $6394(80.0)$ & $6437(80.5)$ & 1.3 \\
\hline Commercial & $2376(21.6)$ & $3712(17.6)$ & 9.9 & $1603(20.0)$ & $1560(19.5)$ & 1.3 \\
\hline Quan-CCI, mean (SD) & $3.3(2.4)$ & $3.3(2.5)$ & 0.5 & $3.3(2.5)$ & $3.3(2.5)$ & 0.9 \\
\hline \multicolumn{7}{|c|}{ COPD-related exacerbations, mean (SD) } \\
\hline Overall & $0.50(0.81)$ & $0.50(0.83)$ & 0.5 & $0.50(0.82)$ & $0.49(0.80)$ & 1.0 \\
\hline Moderate $^{\mathrm{d}}$ & $0.35(0.69)$ & $0.27(0.63)$ & 11.6 & $0.32(0.66)$ & $0.31(0.65)$ & 1.3 \\
\hline Severe $^{\mathrm{e}}$ & $0.15(0.42)$ & $0.23(0.52)$ & 17.3 & $0.18(0.47)$ & $0.18(0.44)$ & 0.1 \\
\hline \multicolumn{7}{|c|}{ Patients with COPD-related exacerbations, $n$ (\%) } \\
\hline Overall & $3897(35.4)$ & $7587(36.1)$ & 1.4 & $2829(35.4)$ & $2883(36.1)$ & 1.4 \\
\hline Moderate $^{\mathrm{d}}$ & $2459(22.3)$ & $3436(16.3)$ & 15.2 & $1557(19.5)$ & $1554(19.4)$ & 0.1 \\
\hline Severe $^{\mathrm{e}}$ & $1438(13.1)$ & $4151(19.7)$ & 18.0 & $1272(15.9)$ & $1329(16.6)$ & 1.9 \\
\hline \multicolumn{7}{|c|}{ Respiratory medications, $n$ (\%) } \\
\hline Systemic corticosteroids & $5505(50.0)$ & $8729(41.5)$ & 17.1 & $3733(46.7)$ & $3719(46.5)$ & 0.4 \\
\hline SABA & $4563(41.4)$ & $7222(34.3)$ & 14.7 & $3131(39.2)$ & $3134(39.2)$ & 0.1 \\
\hline SAMA/SABA & $1100(10.0)$ & $1944(9.2)$ & 2.6 & $762(9.5)$ & $790(9.9)$ & 1.2 \\
\hline Montelukast & $584(5.3)$ & $673(3.2)$ & 10.4 & $395(4.9)$ & $331(4.1)$ & 3.8 \\
\hline SAMA & $182(1.7)$ & $386(1.8)$ & 1.4 & $128(1.6)$ & $147(1.8)$ & 1.8 \\
\hline
\end{tabular}


Table 1 continued

\begin{tabular}{|c|c|c|c|c|c|c|}
\hline & \multicolumn{3}{|c|}{ Unmatched cohorts } & \multicolumn{3}{|c|}{ Propensity score-matched cohorts } \\
\hline & $\begin{array}{l}\text { UMEC/VI } \\
n=11009\end{array}$ & $\begin{array}{l}\text { TIO } \\
n=21039\end{array}$ & $\begin{array}{l}\text { Standardized } \\
\text { diff. }^{\text {a }}(\%)\end{array}$ & $\begin{array}{l}\text { UMEC/VI } \\
n=7997\end{array}$ & $\begin{array}{l}\text { TIO } \\
n=7997\end{array}$ & $\begin{array}{l}\text { Standardized } \\
\left.\text { diff. }^{\text {a }} \%\right)\end{array}$ \\
\hline Methylxanthines & $47(0.4)$ & $84(0.4)$ & 0.4 & $34(0.4)$ & $27(0.3)$ & 1.4 \\
\hline $\begin{array}{l}\text { Chronic antibiotic ( } \geq 6 \text { months } \\
\text { of continuous use) }\end{array}$ & $35(0.3)$ & $56(0.3)$ & 1.0 & $28(0.4)$ & $22(0.3)$ & 1.3 \\
\hline$N$-acetylcysteine & $5(0.0)$ & $16(0.1)$ & 1.2 & $5(0.1)$ & $5(0.1)$ & 0.0 \\
\hline PDE-4 inhibitor & $9(0.1)$ & $31(0.1)$ & 1.9 & $8(0.1)$ & $5(0.1)$ & 1.3 \\
\hline \multicolumn{7}{|l|}{ COPD-related HRU, mean (SD) } \\
\hline Hospitalizations & $0.26(0.64)$ & $0.41(0.83)$ & 20.6 & $0.31(0.71)$ & $0.33(0.66)$ & 2.8 \\
\hline ED visits & $0.27(0.89)$ & $0.35(1.16)$ & 7.4 & $0.31(0.99)$ & $0.32(0.91)$ & 1.3 \\
\hline Outpatient visits & $3.2(6.7)$ & $2.7(7.3)$ & 7.9 & $3.1(6.9)$ & $3.0(8.7)$ & 0.8 \\
\hline Other visits ${ }^{\mathrm{f}}$ & $1.5(4.1)$ & $1.9(5.0)$ & 9.2 & $1.5(4.2)$ & $1.6(4.2)$ & 1.4 \\
\hline \multicolumn{7}{|c|}{ COPD-related medical costs, USD 2019, mean (SD) } \\
\hline Total medical costs & $\begin{array}{l}\$ 10,085 \\
\quad(28,144)\end{array}$ & $\begin{array}{l}\$ 14,251 \\
\quad(37,790)\end{array}$ & 12.5 & $\begin{array}{l}\$ 11,335 \\
\quad(31,071)\end{array}$ & $\begin{array}{l}\$ 11,738 \\
\quad(27,462)\end{array}$ & 1.4 \\
\hline Hospitalizations & $\begin{array}{l}\$ 6091 \\
\quad(22,290)\end{array}$ & $\begin{array}{l}\$ 9969 \\
\quad(32,904)\end{array}$ & 13.8 & $\begin{array}{l}\$ 7304 \\
\quad(24,727)\end{array}$ & $\begin{array}{l}\$ 7693 \\
\quad(23,045)\end{array}$ & 1.6 \\
\hline ED visits & $\begin{array}{l}\$ 1348 \\
\quad(8365)\end{array}$ & $\begin{array}{l}\$ 1946 \\
\quad(10,620)\end{array}$ & 6.3 & $\begin{array}{l}\$ 1529 \\
\quad(9524)\end{array}$ & $\begin{array}{l}\$ 1551 \\
\quad(7421)\end{array}$ & 0.3 \\
\hline Outpatient visits & $\begin{array}{l}\$ 2353 \\
\quad(9045)\end{array}$ & $\begin{array}{l}\$ 1991 \\
\quad(10,732)\end{array}$ & 3.6 & $\begin{array}{l}\$ 2206 \\
\quad(8889)\end{array}$ & $\begin{array}{l}\$ 2201 \\
\quad(10,300)\end{array}$ & 0.0 \\
\hline
\end{tabular}

COPD chronic obstructive pulmonary disease, diff difference, $E D$ emergency department, $H R U$ healthcare resource utilization, $P D E-4$ phosphodiesterase-4, Quan-CCI Quan-Charlson Comorbidity Index, $S A B A$ short-acting $\beta_{2}$-agonist, $S A M A$ short-acting muscarinic antagonist, $S D$ standard deviation, TIO tiotropium, UMEC/VI umeclidinium/vilanterol, USD United States dollars

${ }^{a}$ For continuous variables, the standardized difference was calculated by dividing the absolute difference in means of the control and the case by the pooled SD of both cohorts. The pooled SD is the square root of the average of the squared SD; for dichotomous variables, the standardized difference is calculated using the following equation, where $\mathrm{P}$ is the respective proportion of patients in each cohort: $\left|\left(P_{\text {case }}-P_{\text {control }}\right)\right| / \sqrt{ }\left[\left(P_{\text {case }}\left(1-P_{\text {case }}\right)+P_{\text {control }}\left(1-P_{\text {control }}\right)\right) / 2\right]$

${ }^{b}$ From index date until death, end of eligibility, or end of data availability

c From the index date until discontinuation, a switch to a non-index medication, death, end of eligibility, or end of data availability

${ }^{d}$ Defined as an outpatient or ED visit with a primary diagnosis of COPD and $\geq 1$ dispensing/administration of a systemic corticosteroid or guideline-recommended antibiotic within \pm 5 days

e Defined as an inpatient hospitalization with a diagnosis code for COPD in the primary position

${ }^{\mathrm{f}}$ Includes visits such as home services and hospice 


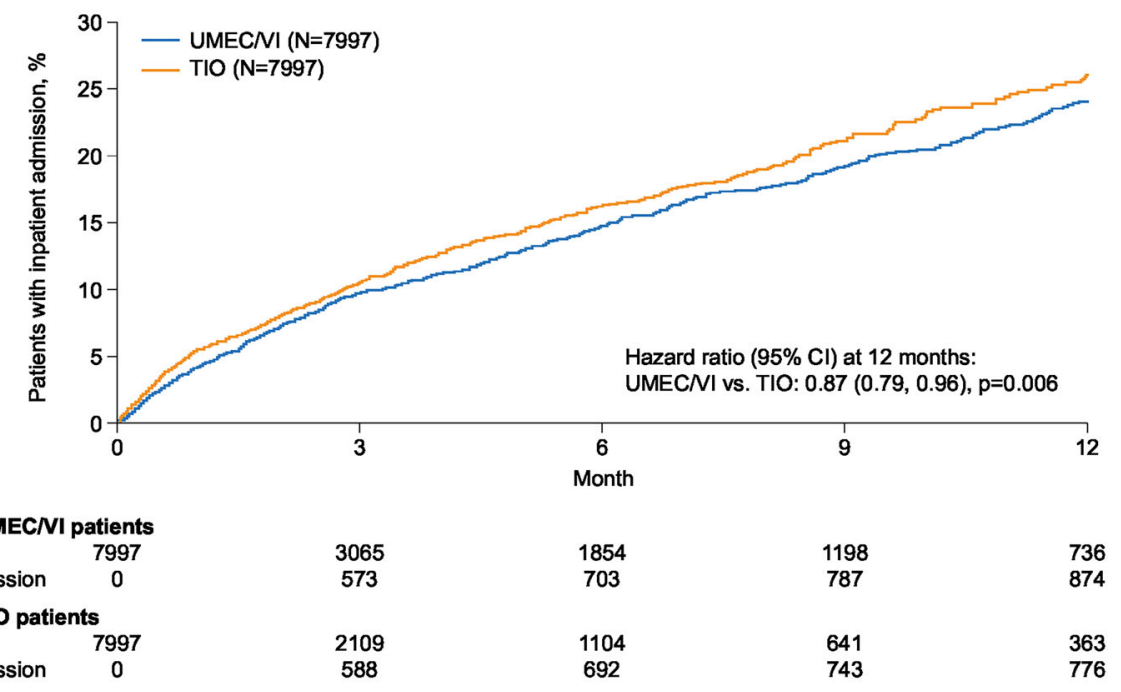

Fig. 3 Time to first on-treatment COPD-related inpatient admission. $C I$ confidence interval, COPD chronic obstructive pulmonary disease, TIO tiotropium, UMEC umeclidinium, $V I$ vilanterol

Table 2 Rate of inpatient admissions

\begin{tabular}{lll}
\hline & UMEC/VI & TIO \\
$(\boldsymbol{n}=7997)$ & $7997)$ & $91.8(99.0)$ \\
\hline On-treatment period, ${ }^{2}$ days, mean (SD) & $124.4(118.3)$ & 2010 \\
Total person-years & 2725 & 971 \\
COPD-related inpatient admissions & 1056 & 0.132 \\
Rate of COPD-related inpatient admissions per 100 person-days & 0.106 & $0.80(0.72,0.92) ; p=0.008$ \\
Rate ratio vs. TIO (95\% CI) & \\
\hline
\end{tabular}

$C I$ confidence interval, $C O P D$ chronic obstructive pulmonary disease, SD standard deviation, TIO tiotropium, UMEC/VI umeclidinium/vilanterol

${ }^{a}$ From the index date until discontinuation, a switch to a non-index medication, death, end of eligibility, or end of data availability

the UMEC/VI and TIO cohorts had an all-cause inpatient readmission (Table 3). The cumulative proportions of these events were similar between treatment cohorts (Fig. $4 \mathrm{a}-\mathrm{d}$ ).

Of the 707 and 603 patients who initiated therapy with UMEC/VI and TIO and were eligible for the 90-day readmission analysis, 15.3\% and $16.9 \%$ experienced an all-cause inpatient readmission. Among patients with an initial admission LOS of $1-3$ days, $15.5 \%$ and $19.8 \%$ in the UMEC/VI and TIO cohorts had an all-cause inpatient readmission (Table 3). Mean rates of all-cause and COPD-related inpatient readmissions within 90 days were similar between cohorts (Fig. 5a, b), but were slightly lower in the UMEC/VI cohort than in the TIO cohort for patients with an initial admission LOS of 1-3 days (Fig. 5c, d).

\section{DISCUSSION}

This claims-based observational study found that patients initiating maintenance therapy with UMEC/VI in a real-world clinical setting had a significantly lower risk of COPD-related inpatient admissions, and experienced 20\% 
Table 3 Inpatient readmissions within 30 and 90 days

\section{UMEC/VI}

TIO

Readmissions within 30 days

Patients with a first admission, ${ }^{\mathrm{a}} n$ 840

717

All-cause inpatient readmission, $n$ (\%)

Mean rate $(\mathrm{SD})$

COPD-related inpatient readmission, $n$ (\%)

Mean rate $(\mathrm{SD})$

Patients with a first admission LOS of $1-3$ days, $n$

All-cause inpatient readmission, $n$ (\%)

Mean rate $(\mathrm{SD})$

COPD-related inpatient readmission, $n(\%)$

Mean rate $(\mathrm{SD})$

Readmissions within 90 days

Patients with a first admission, ${ }^{a} n$

All-cause inpatient readmission, $n$ (\%)

Mean rate (SD)

COPD-related inpatient readmission, $n$ (\%)

Mean rate $(\mathrm{SD})$

Patients with a first admission LOS of 1-3 days, $n$

All-cause inpatient readmission, $n$ (\%)

Mean rate (SD)

COPD-related inpatient readmission, $n$ (\%)

Mean rate (SD)
707

603

$98(11.7)$

$84(11.7)$

$0.14(0.46)$

$0.13(0.38)$

$94(11.2)$

$76(10.6)$

$0.13(0.44)$

$0.12(0.36)$

248

193

$26(10.5)$

$24(12.4)$

$0.16(0.63)$

$0.15(0.46)$

25 (10.1)

22 (11.4)

$0.14(0.58)$

$0.13(0.44)$

108 (15.3)

102 (16.9)

$0.21(0.62)$

$0.23(0.63)$

$99(14.0)$

93 (15.4)

$0.19(0.57)$

$0.20(0.56)$

220

162

34 (15.5)

32 (19.8)

$0.25(0.77)$

$0.30(0.86)$

$30(13.6)$

30 (18.5)

$0.22(0.71)$
$0.27(0.75)$

COPD chronic obstructive pulmonary disease, $L O S$ length of stay, $S D$ standard deviation, $T I O$ tiotropium, $U M E C / V I$ umeclidinium/vilanterol

${ }^{a}$ For the analysis of 30-day and 90-day readmissions, patients were required to have $\geq 30$ and $\geq 90$ days of continuous eligibility after the index discharge date, respectively

lower rates of such admissions while on treatment, compared with patients initiating TIO. Over $85 \%$ of patients in both treatment cohorts continued on their initial UMEC/VI or TIO therapy following inpatient discharge. These results build on previously demonstrated benefits of UMEC/VI dual therapy, including improved lung function, symptom control, and health-related quality of life compared with TIO monotherapy [11-13].

Among patients eligible for the 30-day readmission analysis, $11.7 \%$ in each treatment cohort had an all-cause readmission. Previous claims-based database and observational studies of patients with COPD have reported readmission rates of $12-19 \%[6,16-18]$; the slightly lower readmission rates in this study may reflect 


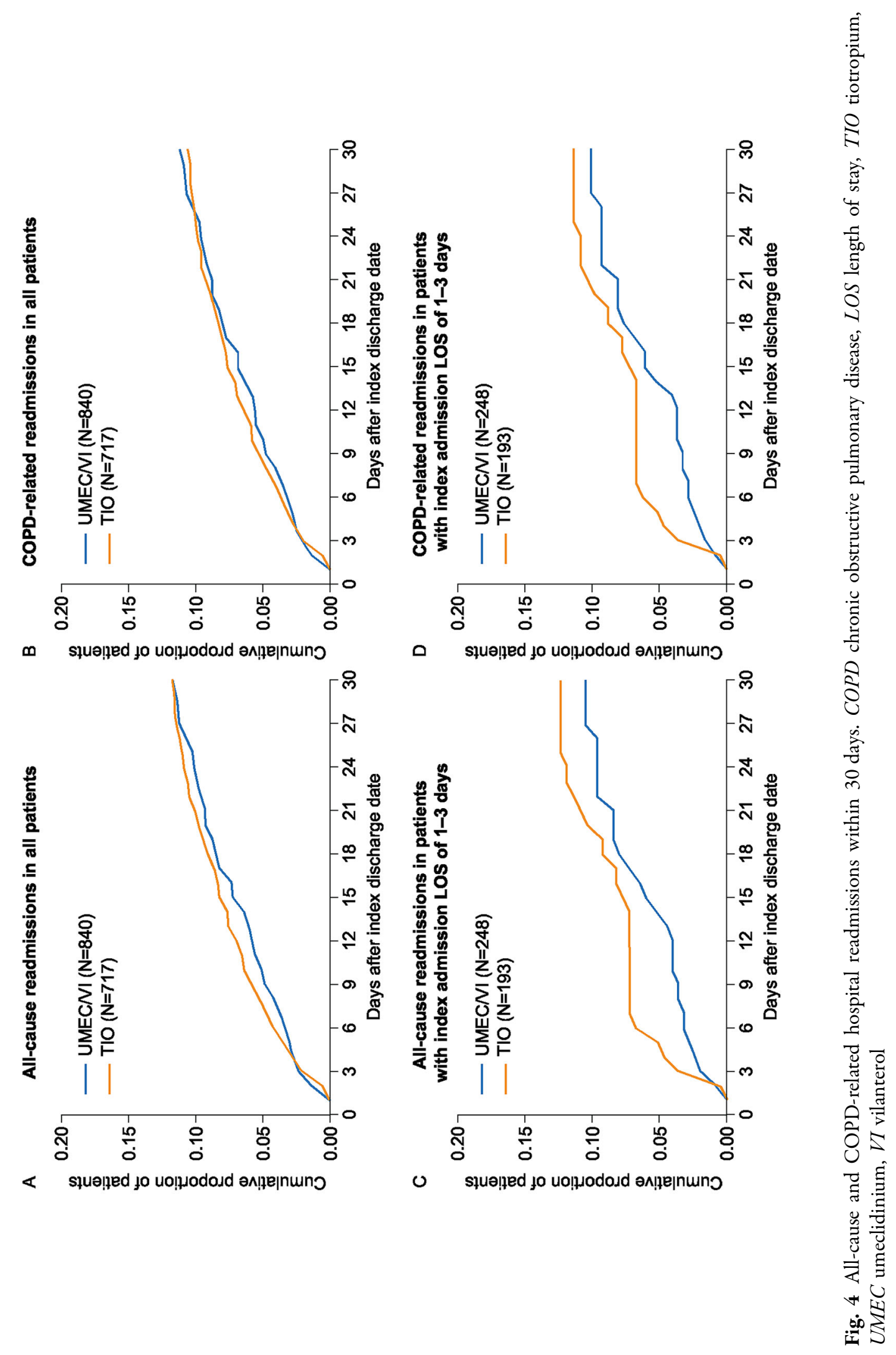



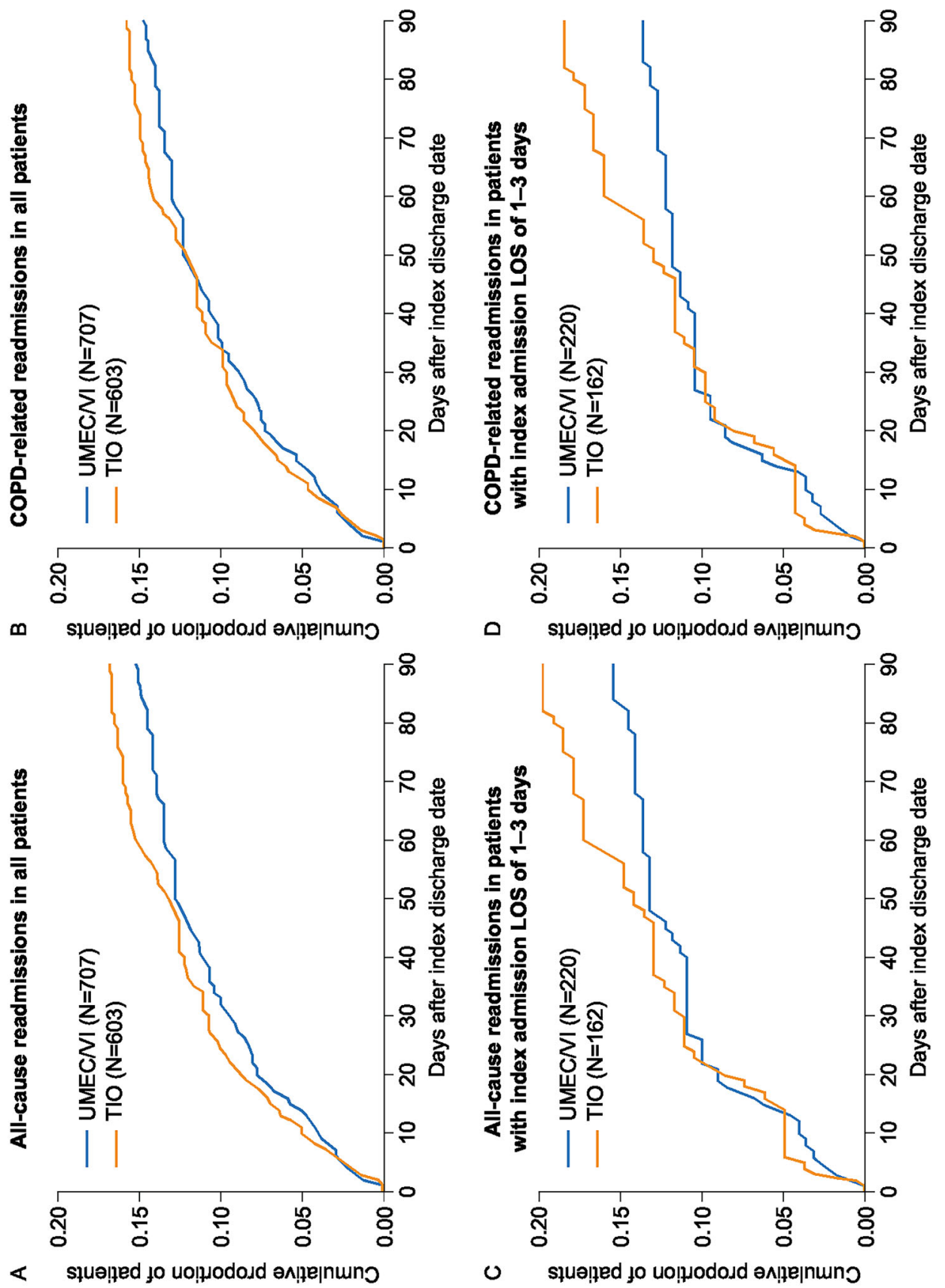

है

słuə|jed to uo|jodosd əx|̣e|nun

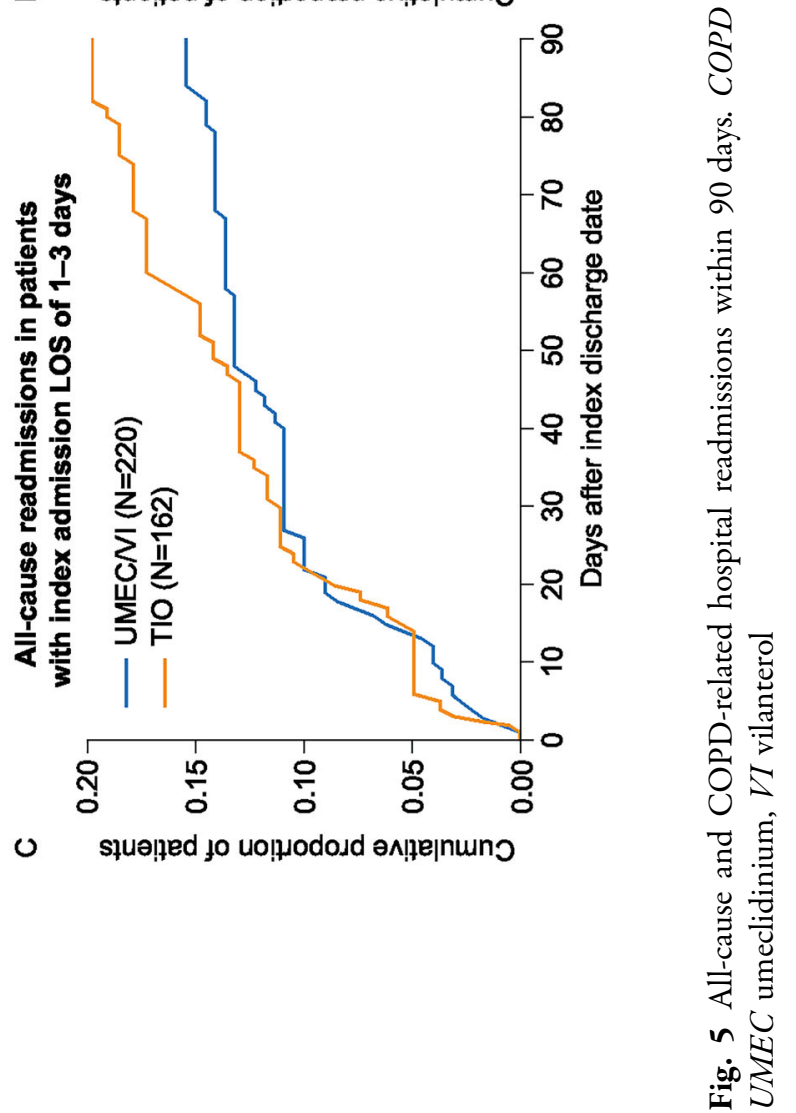


the fact that all patients by definition were on treatment with UMEC/VI or TIO at the time of their initial admission. In the present study, the proportion of patients with all-cause and COPD-related inpatient readmissions within 30 and 90 days was numerically lower with UMEC/VI versus TIO in the subgroup of patients with an initial LOS of 1-3 days. A retrospective cohort study has shown that inpatient LOS is an independent predictor of avoidable inpatient readmissions [19, 20], supporting the clinical relevance of this finding. Taken together, these findings suggest that UMEC/VI compared with TIO can reduce inpatient admissions and readmissions through improved symptom control, and possibly by reducing exacerbations, which may in turn lower the risk of patient mortality $[7,8]$.

The results of the present study highlight the importance of investigating the effects of maintenance treatments on COPD exacerbations in the real-world setting by measuring discrete events such as inpatient admissions and readmissions. Many retrospective database studies assessing the effect of treatment on severe exacerbations (defined by the Global Initiative for COPD as events requiring an emergency department visit or hospitalization) have used algorithms stipulating a certain period of time (i.e., 14 days) to delineate one exacerbation from another $[1,21,22]$. However, in clinical practice, distinguishing one exacerbation from the next can be difficult, particularly as exacerbations have been shown to cluster together in time [23]. Consequently, the reported incidence of exacerbations is dependent on the exacerbation definitions and detection algorithms used [24]. Evaluating the occurrence of an easily identifiable event such as inpatient admission or readmission can therefore provide a consistent assessment of real-world treatment outcomes.

In addition to the impact of hospital admissions on patient prognosis $[4,5,7,8]$, inpatient readmissions are associated with increased healthcare costs $[6,9,10]$, highlighting the importance of reducing these events. A study in patients hospitalized for COPD exacerbations in 2013 and 2014 reported that inpatient readmissions within 30 days incurred $20 \%$ higher healthcare costs than the initial admission [6]. Furthermore, under the CMS Hospital Readmissions Reduction Program, which levies financial penalties against US hospitals with excess inpatient readmissions for COPD $[9,10]$, hospitals can lose up to 3\% of their Medicare payments for all-cause readmissions within 30 days [10]. The findings of the present study show that initial maintenance therapy with UMEC/VI compared with TIO leads to fewer inpatient admissions, and may also be associated with a reduced frequency of readmissions within 30 and 90 days, which could in turn reduce treatment costs. In support of this, a previous study has demonstrated that UMEC/VI is cost-effective and is associated with a reduction in lifetime costs of approximately $\$ 6000$ compared with TIO [14]. Additionally, previous studies have shown that patients initiating TIO had an $87 \%$ higher risk of escalation to triple therapy compared with those initiating UMEC/VI [25]. Notably, around $80 \%$ of patients in the propensity score-matched cohorts in the present study were Medicare enrollees and would therefore be subject to readmission penalties, further supporting the suggestion that reduced readmission rates may contribute to reduced treatment costs.

This study has several strengths. The study population was extracted from a database representing a large, geographically diverse sample of the US population over three full calendar years, and propensity score matching was used to minimize confounding effects of observed patient characteristics on study outcomes. The study also has several limitations, most of which are inherent to claims-based studies, which should be considered when interpreting the results. The presence of a pharmacy claim for a dispensed medication does not necessarily demonstrate that a medication has been taken as prescribed, and there is also the potential for inaccurate claim coding. In addition, claims data do not account for use of over-the-counter medications, medication samples, and any medications received during an inpatient hospital stay. The study did not include any clinical measures to assess lung function or symptoms, as these are not available in claims data. Despite propensity score matching, there is still the 
possibility of confounding due to treatment cohort differences in unmeasured variables such as the degree of airway obstruction or current smoking status, which are associated with lung function decline [26]. Finally, these results may have limited generalizability to the uninsured US population, or non-US populations.

\section{CONCLUSIONS}

These findings highlight the real-world benefits of initiating maintenance therapy with UMEC/VI dual therapy over TIO monotherapy in reducing COPD-related inpatient admissions and all-cause or COPD-related readmissions among patients with COPD. These reductions in admissions may translate to better health outcomes and reduced healthcare costs for patients with COPD initiating maintenance therapy with UMEC/VI compared with TIO.

\section{ACKNOWLEDGEMENTS}

Funding. This study (212477/HO-19-19895) and the journal's Rapid Service Fee were funded by GSK. All authors had full access to all of the data in this study and take complete responsibility for the integrity of the data and accuracy of the data analysis.

Authorship. All named authors meet the International Committee of Medical Journal Editors (ICMJE) criteria for authorship for this article, take responsibility for the integrity of the work as a whole, and have given their approval for this version to be published. DS and $\mathrm{BH}$ were involved in analysis/interpretation of the study data. RR and CM were involved in conception/design of the study and analysis/ interpretation of the study data. GG, FL, MSD, and SDM were involved in conception/design of the study, acquisition of data, and analysis/interpretation of the study data. QS was involved in conception/design of the study.

Medical Writing, Editorial, and Other Assistance. The authors would like to thank
Dr. Lee Baylis (GSK) for his role in the design and conduct of the study. Editorial support (in the form of writing assistance, including development of the initial draft, assembling tables and figures, collating authors' comments, grammatical editing. and referencing) was provided by Mark Condon, DPhil, and Ellen Barker, $\mathrm{PhD}$, at Fishawack Indicia Ltd, UK, and was funded by GSK.

Disclosures. David Slade, Riju Ray, Qin Shen, and Beth Hahn are GSK employees and own stock/shares in GSK, which funded the study. Chad Moretz was an employee of GSK at the time of the study, and is currently an employee of Invitae. Guillaume Germain, François Laliberté, Mei Sheng Duh, and Sean D. MacKnight are employees of Analysis Group, Inc., which was contracted by GSK to conduct the study. Optum's de-identified Clinformatics Data Mart Database is a registered trademark of OptumInsight, Eden Prairie, MN, USA.

Compliance with Ethics Guidelines. The study was designed and conducted in accordance with the principles of the 1964 Declaration of Helsinki and its later amendments. The study used fully de-identified retrospective claims data, which were compliant with the patient requirements of the Health Insurance Portability and Accountability Act of 1996 (HIPAA), and as such was not classified as research involving human participants. Therefore, institutional review board approval was not required.

Data Availability. Information on GlaxoSmithKline's (GSK) data-sharing commitments and requesting access to anonymized individual participant data and associated documents from GSK-sponsored studies can be found at www.clinicalstudydatarequest.com. The datasets analyzed during the current study are not publicly available because they are contained in a database owned by Optum and contain proprietary elements. Therefore, it cannot be broadly disclosed or made publicly available at this time. The disclosure of these data to third-party clients assumes certain data security and privacy protocols are in place and 
that the third-party client has executed Optum's standard license agreement which includes restrictive covenants governing the use of the data.

Open Access. This article is licensed under a Creative Commons Attribution-NonCommercial 4.0 International License, which permits any non-commercial use, sharing, adaptation, distribution and reproduction in any medium or format, as long as you give appropriate credit to the original author(s) and the source, provide a link to the Creative Commons licence, and indicate if changes were made. The images or other third party material in this article are included in the article's Creative Commons licence, unless indicated otherwise in a credit line to the material. If material is not included in the article's Creative Commons licence and your intended use is not permitted by statutory regulation or exceeds the permitted use, you will need to obtain permission directly from the copyright holder. To view a copy of this licence, visithttp://creativecommons.org/licenses/by$\mathrm{nc} / 4.0 /$.

\section{REFERENCES}

1. Global Initiative for Chronic Obstructive Lung Disease (GOLD). Global Strategy for the Diagnosis, Management, and Prevention of Chronic Obstructive Pulmonary Disease. 2020. Available from: https://goldcopd.org/wp-content/uploads/2019/ 12/GOLD-2020-FINAL-ver1.2-03Dec19_WMV.pdf. (Accessed 4 May 2020).

2. Dhamane AD, Moretz C, Zhou Y, et al. COPD exacerbation frequency and its association with health care resource utilization and costs. Int J Chron Obstruct Pulmon Dis. 2015;10:2609-18.

3. Iheanacho I, Zhang S, King D, Rizzo M, Ismaila AS. Economic burden of Chronic Obstructive Pulmonary Disease (COPD): a systematic literature review. Int J Chron Obstruct Pulmon Dis. 2020;15: 439-60.

4. Ho TW, Tsai YJ, Ruan SY, et al. In-hospital and oneyear mortality and their predictors in patients hospitalized for first-ever chronic obstructive pulmonary disease exacerbations: a nationwide population-based study. PLoS ONE. 2014;9: e114866.
5. Müllerova H, Maselli DJ, Locantore $\mathrm{N}$, et al. Hospitalized exacerbations of COPD. Chest. 2015;147:999-1007.

6. Jacobs DM, Noyes K, Zhao J, et al. Early hospital readmissions after an acute exacerbation of chronic obstructive pulmonary disease in the nationwide readmissions database. Ann Am Thorac Soc. 2018;15:837-45.

7. Hartl S, Lopez-Campos JL, Pozo-Rodriguez F, et al. Risk of death and readmission of hospital-admitted COPD exacerbations: European COPD audit. Eur Respir J. 2016;47:113-21.

8. Seneff MG, Wagner DP, Wagner RP, Zimmerman JE, Knaus WA. Hospital and 1-year survival of patients admitted to intensive care units with acute exacerbation of chronic obstructive pulmonary disease. JAMA. 1995;274:1852-7.

9. Press VG, Au DH, Bourbeau J, et al. Reducing chronic obstructive pulmonary disease hospital readmissions. An official American Thoracic Society workshop report. Ann Am Thorac Soc. 2019;16: 161-70.

10. Centers for Medicare \& Medicaid Services. Centers for Medicare \& Medicaid Services Hospital Readmissions Reduction Program (HRRP). 2016. Available from: https://www.cms.gov/medicare/ medicare-fee-for-service-payment/acuteinpatientp ps/readmissions-reduction-program. (Accessed 8 June 2020).

11. Decramer M, Anzueto A, Kerwin E, et al. Efficacy and safety of umeclidinium plus vilanterol versus tiotropium, vilanterol, or umeclidinium monotherapies over 24 weeks in patients with chronic obstructive pulmonary disease: results from two multicentre, blinded, randomised controlled trials. Lancet Respir Med. 2014;2:472-86.

12. Maleki-Yazdi MR, Kaelin T, Richard N, Zvarich M, Church A. Efficacy and safety of umeclidinium/vilanterol $62.5 / 25 \mathrm{mcg}$ and tiotropium $18 \mathrm{mcg}$ in chronic obstructive pulmonary disease: results of a 24-week, randomized, controlled trial. Respir Med. 2014; 108:1752-60.

13. Kerwin EM, Kalberg CJ, Galkin DV, et al. Umeclidinium/vilanterol as step-up therapy from tiotropium in patients with moderate COPD: a randomized, parallel-group, 12-week study. Int J Chron Obstruct Pulmon Dis. 2017;12:745-55.

14. Wilson MR, Patel JG, Coleman A, McDade CL, Stanford RH, Earnshaw SR. Cost-effectiveness analysis of umeclidinium/vilanterol for the management of patients with moderate to very severe COPD using an economic model. Int J Chron Obstruct Pulmon Dis. 2017;12:997-1008. 
15. Elixhauser A, Steiner C, Harris DR, Coffey RM. Comorbidity measures for use with administrative data. Med Care. 1998;36:8-27.

16. Ford ES. Hospital discharges, readmissions, and ED visits for COPD or bronchiectasis among US adults: findings from the nationwide inpatient sample 2001-2012 and Nationwide Emergency Department Sample 2006-2011. Chest. 2015;147:989-98.

17. Guerrero M, Crisafulli E, Liapikou A, et al. Readmission for acute exacerbation within 30 days of discharge is associated with a subsequent progressive increase in mortality risk in COPD patients: a long-term observational study. PLoS ONE. 2016;11: e0150737.

18. Simmering JE, Polgreen LA, Comellas AP, Cavanaugh JE, Polgreen PM. Identifying patients with COPD at high risk of readmission. Chronic Obstr Pulm Dis. 2016;3:729-38.

19. Donzé J, Aujesky D, Williams D, Schnipper JL. Potentially avoidable 30-day hospital readmissions in medical patients: derivation and validation of a prediction model. JAMA Intern Med. 2013;173: 632-8.

20. Donzé JD, Williams MV, Robinson EJ, et al. International validity of the hospital score to predict 30-day potentially avoidable hospital readmissions. JAMA Intern Med. 2016;176:496-502.

21. Buikema AR, Brekke L, Anderson A, et al. The effect of delaying initiation with umeclidinium/vilanterol in patients with COPD: an observational administrative claims database analysis using marginal structural models. Multidiscip Respir Med. 2018;13: 38.

22. Moretz C, Sharpsten L, Bengtson LG, et al. Realworld effectiveness of umeclidinium/vilanterol versus fluticasone propionate/salmeterol as initial maintenance therapy for chronic obstructive pulmonary disease (COPD): a retrospective cohort study. Int J Chron Obstruct Pulmon Dis. 2019;14: 1721-37.

23. Hurst JR, Donaldson GC, Quint JK, Goldring JJ, Baghai-Ravary R, Wedzicha JA. Temporal clustering of exacerbations in chronic obstructive pulmonary disease. Am J Respir Crit Care Med. 2009;179: 369-74.

24. Trappenburg JC, van Deventer AC, Troosters T, et al. The impact of using different symptom-based exacerbation algorithms in patients with COPD. Eur Respir J. 2011;37:1260-8.

25. Hahn B, Hull M, Blauer-Peterson C, Buikema AR, Ray R, Stanford RH. Rates of escalation to triple COPD therapy among incident users of LAMA and LAMA/LABA. Respir Med. 2018;139:65-71.

26. Celli BR, Thomas NE, Anderson JA, et al. Effect of pharmacotherapy on rate of decline of lung function in chronic obstructive pulmonary disease: results from the TORCH study. Am J Respir Crit Care Med. 2008;178:332-8. 